\title{
-megasains
}

\section{Analisis Siklogenesis Siklon Tropis Dahlia Menggunakan Citra Satelit Himawari}

\author{
Zenita Endriani ${ }^{1}$ dan Annisa Fauziah ${ }^{2}$ \\ ${ }^{1}$ Stasiun Meteorologi Fransiskus Xaverius Seda Sikka \\ ${ }^{2}$ Stasiun Meteorologi Sultan Thaha Jambi
}

\begin{abstract}
Abstrak. Siklon tropis merupakan suatu sistem tekanan rendah yang muncul di lintang tropis yang terbentuk dan berkembang di wilayah lautan luas, dampak dari adanya siklon tropis jika melintas mendekati daratan adalah dapat menyebabkan kerusakan dan bencana di beberapa wilayah. Indonesia menjadi salah satu wilayah yang terdampak adanya Siklon Tropis. Untuk memprakirakan kemunculan dan kekuatan dari siklon tropis dibutuhkan analisis, baik dari pembentukan hingga tahap meluruh (siklogenesis). Dalam penelitian ini penulis menggunakan satelit Himawari-8 dan teknik Dvorak untuk menganalisis Siklon Tropis Dahlia yang baru-baru ini melewati wilayah perairan selatan Indonesia. Penulis menganalisis siklogenesis dahlia dari lapisan bawah hingga lapisan atas troposfer. Adapun parameter yang dianalisis baik dari pola struktur pembentukan awan, vortisitas, kelembaban udara dan windshear vertikal. Hasil analisis menunjukkan terjadinya pola perubahan struktur pembentukan awan dari hari ke hari, vortisitas maksimum menunjukkan nilai yang sangat signifikan ketika terbentuknya mata badai, kelembaban maksimum terjadi pada sabuk pumpunan awan, windshear vertikal yang cenderung bernilai lemah selama pertumbuhan siklon serta pembentukan konvergensi yang semakin terpola ketika tahap matang dan perlahan semuanya meluruh ketika tahap punah.
\end{abstract}

(Kata kunci: kata Dvorak, Himawari-8, Siklon Tropis, Siklogenesis)

Abstrak. Tropical cyclone is a system of low pressure that appears in tropical latitudes that formed and developing in large areas of the ocean. The impact of the presence of tropical cyclones crossing the land can cause damage and disaster in some areas. Indonesia is one of the regions affected by the presence of tropical cyclones. To predict the emergence and strength of tropical cyclones, analysis is needed, both from formation to decaying stage (cyclogenesis). In this study the authors used himawari satellites and dvorak techniques to analyze the Tropical Cyclone Dahlia which recently passed the southern waters of Indonesia. The authors analyze the dahlia cyclogenesis from the lower layer to the upper layer. The parameters that are analyzed are from the structure pattern of cloud formation, vorticity, humidity and wind speed. The results of the analysis show that there is a pattern of changes in cloud formation structure from day to day, maximum vorticity shows a very significant value in the formation stage of the storm eye, maximum relative humidity occurs in the cloud pumping belt, increased wind speed and the formation of convergence are increasingly patterned at the mature stage, and slowly all of it decays when the stage goes extinct.

(Keywords: Dvorak, Himawari-8, Tropical Cylones, Cyclogenesis)

\section{Pendahuluan}

Siklon tropis Dahlia melewati perairan selatan Indonesia dengan waktu hidup dari tanggal 27 November hingga 03 Desember 2017. Satelit Himawari-8 milik JMA (Japan Meteorological Agency) telah merekam secara keseluruhan dari tahap muncul, tumbuh hingga punahnya Siklon Tropis Dahlia. Pemanfaatan kanal IR (Infra Red) dari satelit Himawari-8 merupakan salah satu metode yang sangat efektif untuk memonitor siklon tropis Dahlia dikarenakan kanal IR memiliki resolusi spasial hingga $2 \mathrm{~km}$ dan resolusi temporal setiap 10 menit, sehingga resolusi suhu puncak awan yang terpantau juga sangat tinggi. Resolusi suhu puncak awan dari kanal IR tersebut dapat dimanfaatkan dalam analisis Dvorak[6] untuk memprakirakan nilai intensitas Siklon Tropis Dahlia dimana akan dibahas dalam penelitian ini.

Selain analisis Dvorak, analisis siklogenesis Dahlia dari lapisan bawah hingga atas juga dilakukan dalam penelitian ini. Enam 
kondisi umum yang diperlukan siklon tropis dalam pembentukan dan pertumbuhannya (siklogenesis) telah dibahas oleh Gray [2], antara lain:

1. Perairan yang cukup hangat sebagai pemasok energi siklon tropis (suhu permukaan laut $>26^{\circ} \mathrm{C}$ hingga kedalaman $60 \mathrm{~m}$ ),

2. Kelembaban udara relatif yang cukup lembab di lapisan troposfer tengah (700 hPa),

3. Kondisi udara labil,

4. Vortisitas relatif kuat di lapisan troposfer bawah,

5. Shear vertikal lemah di area siklogenesis,

6. Terjadi pada lintang $5^{\circ}$ atau lebih menjauhi ekuator.

Dari enam kondisi tersebut, yang akan dibahas adalah parameter kelembaban udara relatif, vortisitas relatif dan shear vertikal serta tambahan parameter indeks konvektif yang berpengaruh terhadap siklogenesis Dahlia.

\section{Metode Penelitian}

Data yang digunakan dalam penelitian ini merupakan data citra kanal infrared (IR) produk dari satelit Himawari-8 milik Japan Meteorological Agency dengan waktu perekaman data saat terjadinya siklon tropis Dahlia dari tanggal 27 November hingga 2 Desember 2017. Metode yang digunakan dalam penelitian ini adalah pemanfaatan satelit Himawari untuk analisis teknik dvorak[1] pada siklon tropis Dahlia dan metode analisis siklogenesis terhadap pola struktur pembentukan awan, vortisitas, kelambaban dan kecepatan angin serta indeks konvektif siklon tropis Dahlia.

Tahapan pemanfaatan teknik Dvorak mengacu pada penelitian Krismianto [4] yaitu sebagai berikut :

1. Data satelit Himawari-8 kanal IR dengan format netcdf diolah pada aplikasi GrADs versi 2.0, untuk dikonversi menjadi data suhu puncak awan (TBB= Temperature of a Black Body) dalam satuan Kelvin (K).

2. Data TBB digunakan untuk mencari nilai indeks konvektif menggunakan rumus $255 \mathrm{~K}-$ TBB. Threshold $255 \mathrm{~K}$ tersebut diperoleh dari hasil penelitian Murakhami (1987).

3. Identifikasi pertumbuhan dan pergerakan siklon tropis Dahlia melalui pengamatan visual terhadap citra kanal IR satelit Himawari-8.

4. Prediksi nilai Dvorak T-Number dengan cara membandingkan pengamatan visual dengan diagram Dvorak.

Identifikasi Dvorak T-Number hingga didapat intensitas siklon tropis berupa laju angin maksimum dan tekanan minimum di atas permukaan laut dengan menggunakan Tabel Dvorak T-Number.

\section{Hasil dan Pembahasan}

\section{Bagian Indeks Konvektif}

Hasil pengolahan data format netcdf kanal Infrared dengan aplikasi GrADs yaitu berupa data indeks konvektif dari tanggal 28 November hingga 02 Desember 2017 memperlihatkan adanya aktivitas konvektif yang kuat di wilayah yang dilalui siklon tropis Dahlia dengan nilai indeks lebih dari 50 . Nilai indeks konvektif berkisar antara 0 hingga 60 dimana semakin tinggi nilai indeksnya maka berarti semakin tinggi aktivitas konvektifnya [4]. Dari gambar dapat dilihat, bibit siklon telah tumbuh pada 28 November 2017. Kemudian siklon mulai memasuki tahap remaja pada tanggal 30 November 2017 ditandai dengan mulai munculnya mata siklon. Siklon tropis Dahlia terus bergerak ke arah tenggara hingga akhirnya mulai melemah pada tanggal 02 Desember 2017.

\section{Nov 201712.00 UTC}

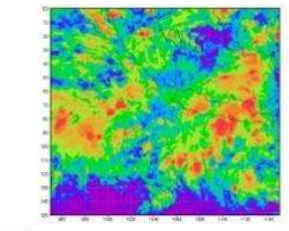

29 Nov 201700.10 UTC

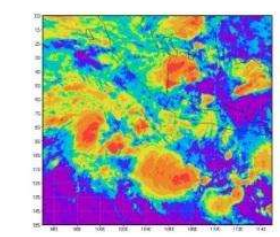

29 Nov 201712.00 UTC

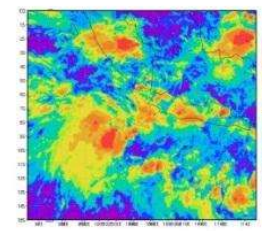

30 Nov 201700.00 UTC

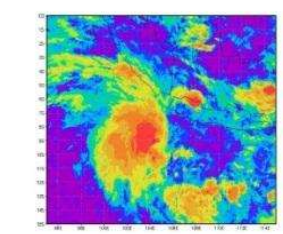

30 Nov 201712.00 UTC
28 Nov 201718.00 UTC

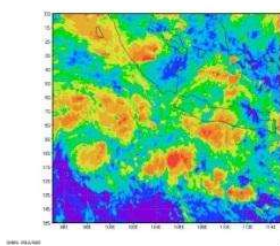

29 Nov 201706.00 UTC

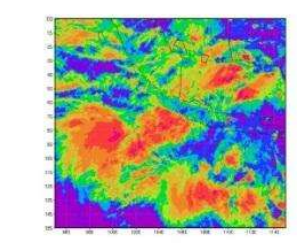

29 Nov 201718.00 UTC

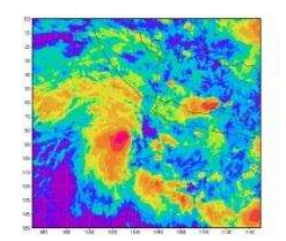

30 Nov 201706.00 UTC

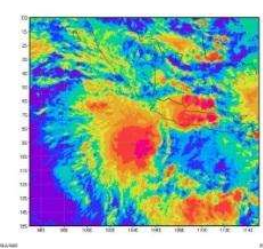

30 Nov 201718.00 UTC 


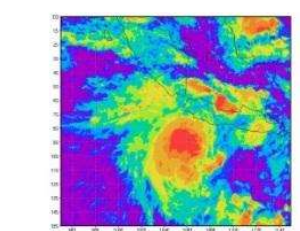

01 Des 201700.00 UTC

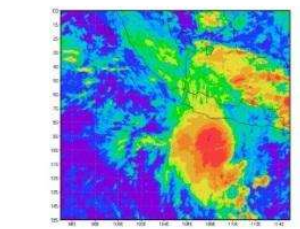

02 Des 201700.00 UTC

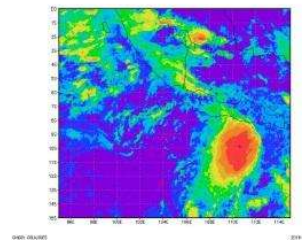

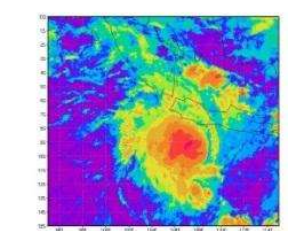

01 Des 201706.00 UTC

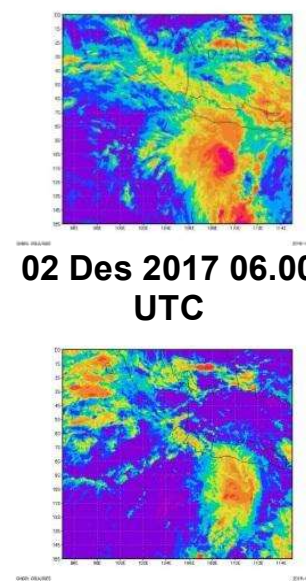

Gambar 1. Indeks konvektif selama siklogenesis Dahlia

\section{Analisis Dvorak}

Untuk mengetahui intensitas siklon tropis Dahlia, digunakan citra EIR (Enhance Infrared) yang dapat dimanfaatkan dalam analisis Dvorak. Perubahan warna pada citra menunjukkan nilai suhu puncak awan. Teknik zoom dilakukan untuk dapat melihat pusaran siklon dengan lebih spesifik.
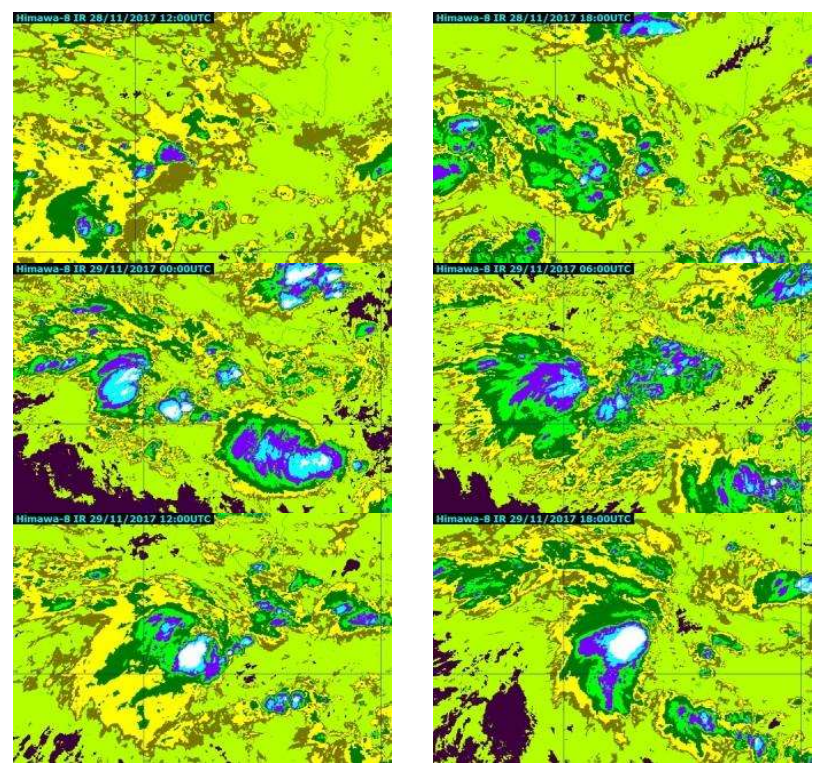
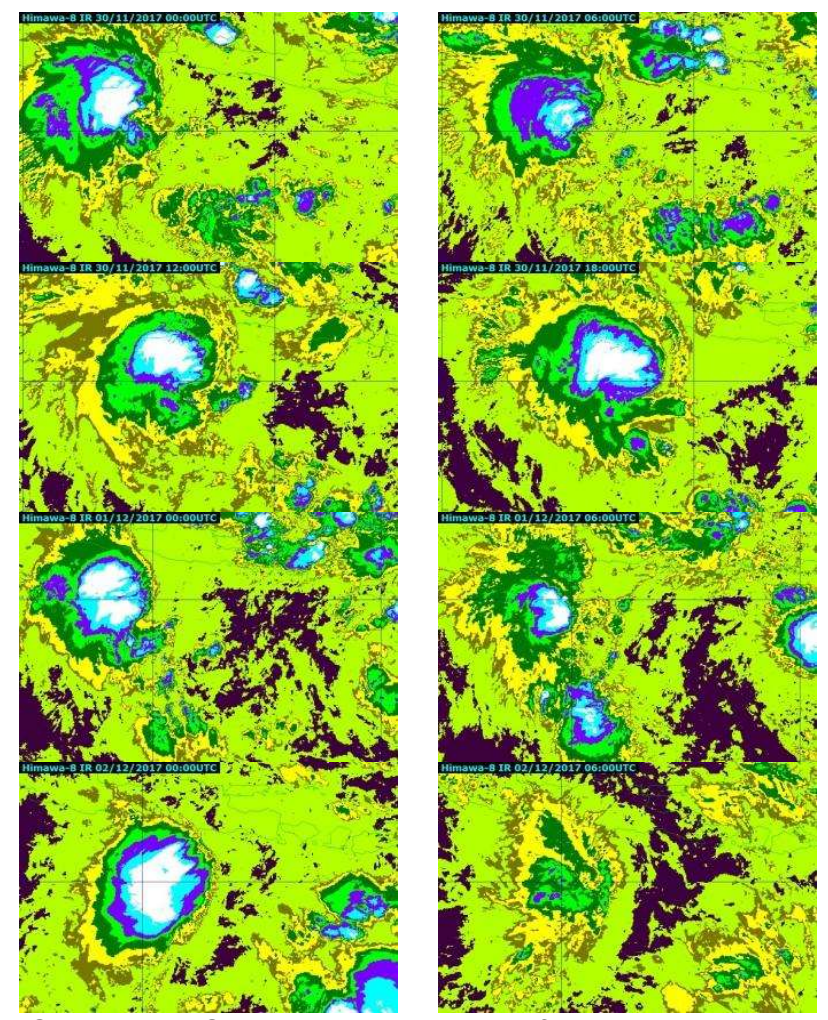

Gambar 2. Citra EIR (Enhance Infrared) dari satelit Himawari-8 selama siklogenesis Dahlia

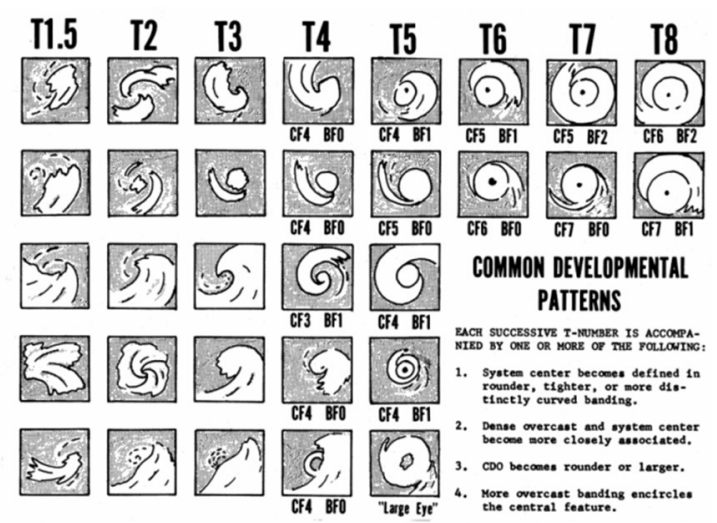

Gambar 3. Diagram Dvorak (Sumber : NOAA, 2005)

Berdasarkan pada gambar 2 yang telah dibandingkan terhadap diagram Dvorak [5] pada gambar 3 , didapatkan nilai $T$-Number untuk tiap gambar, kemudian didapat pula nilai kecepatan angin, kategori dan tekanan udara dalam masa hidup siklon tropis Dahlia. Hal ini dapat dilihat pada tabel 2 .

Tabel 1. Hubungan Dvorak T-Number dengan Intensitas Siklon Tropis 


\begin{tabular}{|c|c|c|c|c|c|c|}
\hline \multirow{2}{*}{ T-Number } & \multicolumn{3}{|c|}{ 1-min Winds } & \multirow{2}{*}{$\begin{array}{l}\text { Category } \\
\text { (SsHS) }\end{array}$} & \multicolumn{2}{|c|}{$\begin{array}{l}\text { Min. Pressure } \\
\text { (millibars) }\end{array}$} \\
\hline & (knots) & (mph) & $(\mathrm{km} / \mathrm{h})$ & & Atlantic & $\begin{array}{c}\text { NW } \\
\text { Pacific }\end{array}$ \\
\hline $1.0-1.5$ & 25 & 29 & 46 & TD & - & - \\
\hline 2.0 & 30 & 35 & 56 & TD & 1009 & 1000 \\
\hline 2.5 & 35 & 40 & 65 & TS & 1005 & 997 \\
\hline 3.0 & 45 & 52 & 83 & TS & 1000 & 991 \\
\hline 3.5 & 55 & 63 & 102 & TS & 994 & 984 \\
\hline 4.0 & 65 & 75 & 120 & Cat 1 & 987 & 976 \\
\hline 4.5 & 77 & 89 & 143 & Cat 1-2 & 979 & 966 \\
\hline 5.0 & 90 & 104 & 167 & Cat 2-3 & 970 & 954 \\
\hline 5.5 & 102 & 117 & 189 & Cat 3 & 960 & 941 \\
\hline 6.0 & 115 & 132 & 213 & Cat 4 & 948 & 927 \\
\hline 6.5 & 127 & 146 & 235 & Cat 4 & 935 & 914 \\
\hline 7.0 & 140 & 161 & 260 & Cat 5 & 921 & 898 \\
\hline 7.5 & 155 & 178 & 287 & Cat 5 & 906 & 879 \\
\hline 8.0 & 170 & 196 & 315 & Cat 5 & 890 & 858 \\
\hline
\end{tabular}

Tabel 2. Hasil Analisis Menggunakan Dvorak T-Number

\begin{tabular}{|c|c|c|c|c|}
\hline Waktu (UTC) & T-Number & $\mathbf{V}(\mathbf{k m} / \mathbf{j a m})$ & Kategori & $\mathbf{P}(\mathbf{m b})$ \\
\hline $11 / 28 / 201712: 00$ & 1.5 & 46 & TD & - \\
\hline $11 / 28 / 201718: 00$ & 1.5 & 46 & TD & - \\
\hline $11 / 29 / 201700: 00$ & 1.5 & 46 & TD & - \\
\hline $11 / 29 / 201706: 00$ & 2 & 56 & TD & 1009 \\
\hline $11 / 29 / 201712: 00$ & 3 & 83 & TS & 1000 \\
\hline $11 / 29 / 201718: 00$ & 3 & 83 & TS & 1000 \\
\hline $11 / 30 / 201700: 00$ & 3 & 83 & TS & 1000 \\
\hline $11 / 30 / 201706: 00$ & 3 & 83 & TS & 1000 \\
\hline $11 / 30 / 201712: 00$ & 3 & 83 & TS & 1000 \\
\hline $11 / 30 / 201718: 00$ & 3 & 83 & TS & 1000 \\
\hline $12 / 1 / 201700: 00$ & 3.5 & 102 & TS & 994 \\
\hline $12 / 1 / 201706: 00$ & 3.5 & 102 & TS & 994 \\
\hline $12 / 1 / 201712: 00$ & 3.5 & 102 & TS & 994 \\
\hline $12 / 1 / 201718: 00$ & 3.5 & 102 & TS & 994 \\
\hline $12 / 2 / 201700: 00$ & 3 & 83 & TS & 1000 \\
\hline $12 / 2 / 201706: 00$ & 3 & 83 & TS & 1000 \\
\hline $12 / 2 / 201712: 00$ & 2.5 & 65 & TS & 1005 \\
\hline $12 / 2 / 201718: 00$ & 2 & 56 & TD & 1009 \\
\hline
\end{tabular}

Dari Tabel 2 dapat diketahui bahwa selama masa hidupnya, intensitas maksimum Dahlia terjadi pada tanggal 1 Desember 2017, dengan T-Number 3.5 , yaitu saat memasuki kategori TS (tropical Storm), kecepatan angin $102 \mathrm{~km} / \mathrm{jam}$ dan tekanan udara minimum mencapai $994 \mathrm{mb}$. Dahlia mulai mengalami penurunan intensitas pada 2 Desember 2017 , dengan T_Number 3 dan nilai kecepatan angin menjadi $8 \overline{3} \mathrm{~km} / \mathrm{jam}$.

\section{Siklogenesis Dahlia}

Gambar 4 menunjukkan perubahan nilai parameter dinamis siklon tropis Dahlia

selama fase siklogenesis. Dari atas ke bawah pada gambar yaitu tanggal 27 November sampai dengan 2 Desember 2017. Bibit siklon tropis Dahlia mulai muncul pada tanggal 27 November 2017, di lokasi yang nilai kelembaban udaranya di lapisan tengah (700 $\mathrm{hPa}$ ) berkisar $90 \%$, vortisitas relatif di lapisan bawah -50 serta wind shear vertikal lemah, merupakan lingkungan yang sangat mendukung dalam pembentukan siklon tropis. Siklon terus tumbuh hingga mencapai tahap remaja pada 30 November 2017, dengan nilai vortisitas meningkat mencapai -100 dan parameter lainnya tetap bernilai konstan. Dahlia terus bergerak ke arah tenggara hingga akhirnya melemah pada tanggal 2 Desember 2017 ditandai nilai vortisitas mengalami penurunan menjadi -50 , sementara parameter lainnya masih bernilai konstan.

\section{WIND}

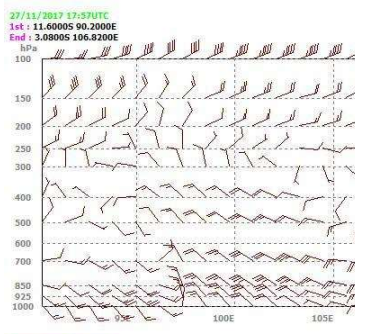

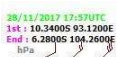
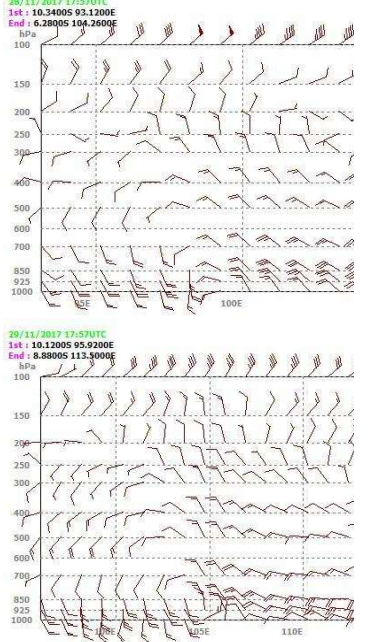

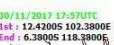

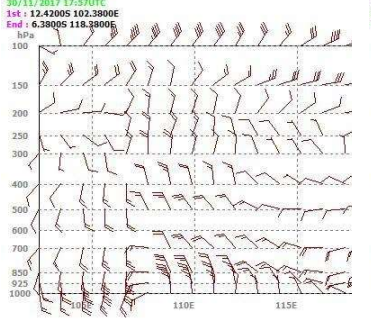

RH
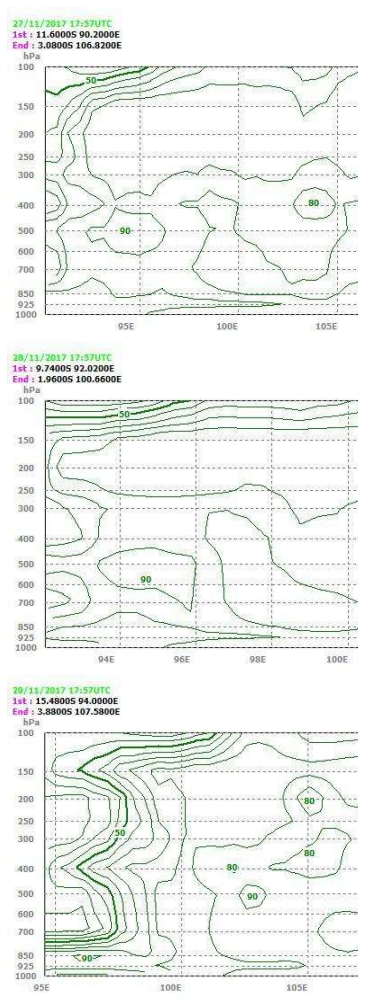

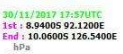

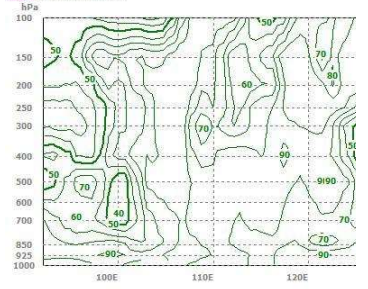



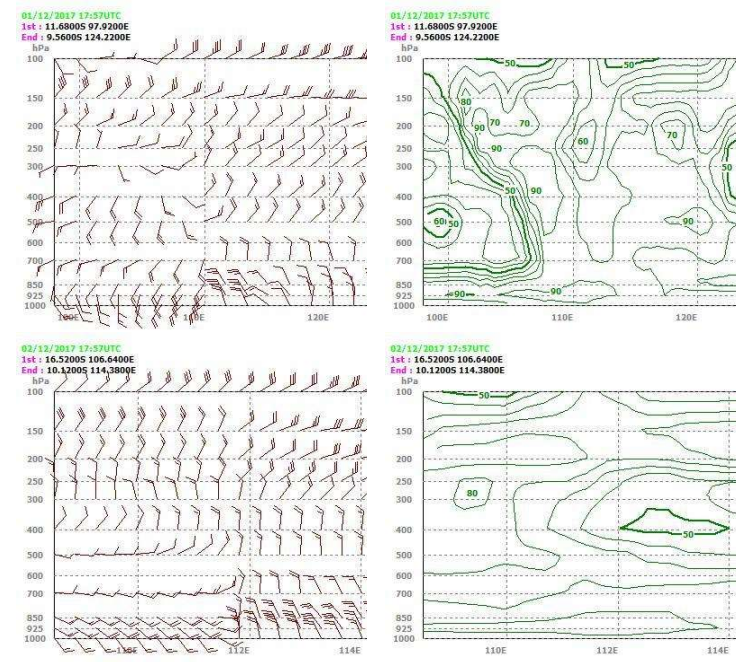

VORTICITY
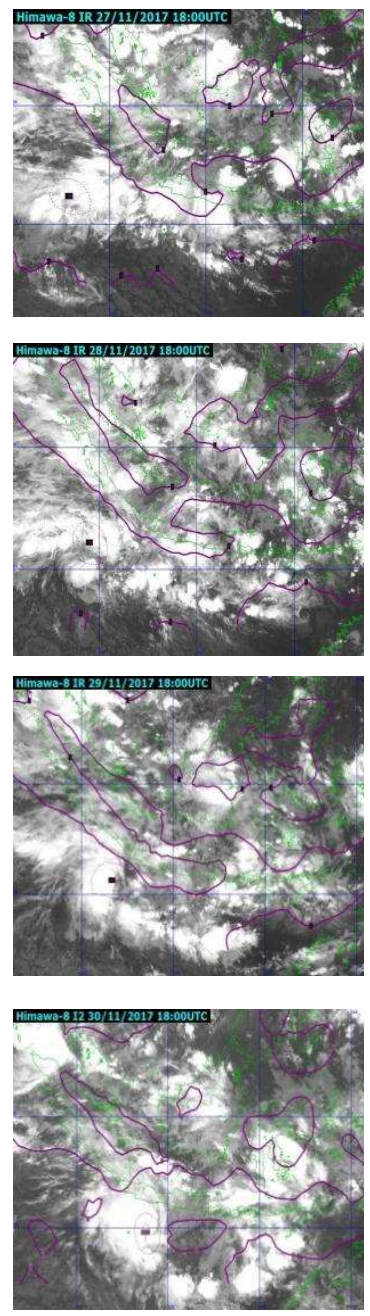
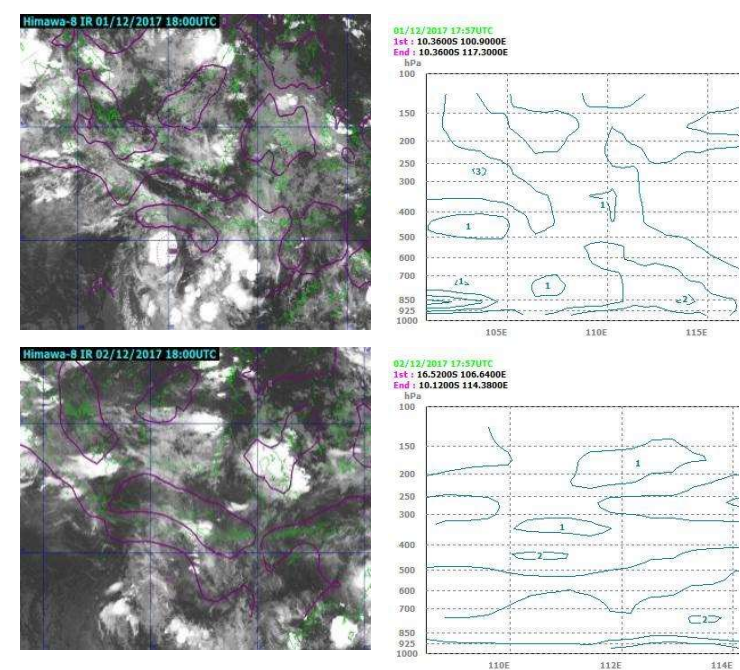

Gambar 4. Parameter Dinamis pada saat siklogenesis Dahlia

\section{Kesimpulan}

Satelit Himawari-8 kanal infrared dapat dimanfaatkan untuk analisis Dvorak dan siklogenesis pada siklon tropis Dahlia. Selama masa hidupnya, intensitas maksimum Dahlia terjadi pada tanggal 1 Desember 2017, dengan T-Number 3.5, yaitu saat memasuki kategori TS (tropical Storm), kecepatan angin $102 \mathrm{~km} / \mathrm{jam}$ dan tekanan udara minimum mencapai $994 \mathrm{mb}$. Parameter Vortisitas Relatif bernilai lebih fluktuatif mengikuti fase siklogenesis Dahlia dibandingkan parameter $\mathrm{RH}$ dan windshear vertikal yang cenderung konstan.

\section{Daftar Pustaka}

[1] Dvorak, V.F., 1973. A Technique for the Analysis and forecasting of Tropical Cyclone Intensities From Satellite Pictures, NOAA, 5-8.

[2] Gray, W. M., 1968. Tropical Cyclone Genesis, Atmospheric Science PAPER No. 234, Colorado State University, Fort Collins, Colorado.

[3] JMA, 2017. SATAID Operation Manual, JMA.

[4] Krismianto, 2015. Analisis Pertumbuhan, Pergerakan, dan Intensitas Siklon Tropis Marcia Berbasis Data Satelit MTSAT, Lembaga Penerbangan dan Antariksa Nasional.

[5] NOAA, 2005. Dvorak Current Intensity Chart, Satellite and Information Service Division, NOAA.

[6] Zeschke, B., 2015. Effective Use of High Temporal and Spatial Resolution Himawari-8 Data, AOMSUC-6 Training Event. http://www.bom.gov.au, diakses 05 Januari 2018 